\title{
ISIDORO DE SEVILHA E A ESPANHA VISIGÓTICA
}

\author{
DANIEL VALLE RIBEIRO \\ Universidade Federal de Minas Gerais
}

\begin{abstract}
Resumo: Após a queda do Império Romano, a lgreja procura definir a atribuiçăo dos poderes em termos de estreita unidade, isto é, sem distingüir o temporal do espiritual. Isidoro de Sevilha aparece como o grande mestre da teologia polftica da Alta Idade Média. Livra a realeza espanhola de seu "pecado original": liberta-se de sua interioridade diamte do Império e exorciza as lembranças nocivas. Ao "inventar" a realeza cristá, confere legitimidade própria ds realezas que se constituem no Ocidente. Mas a noçâo de serviço que o cristianismo atribui ao poder torna o Estado um instrumento de salvaçăo.
\end{abstract}

Palavras-chave: Idade Média, Doutrina polftica, Teocracia.

A Espanha visigótica do século VII oferece a primeira contribuição objetiva à idéia de realeza no Ocidente medieval. Coube a Isidoro de Sevilha traçar-Ihe a doutrina. O bispo espanhol procurou orientar seu trabalho para a solução de problemas concretos, na tentativa de edificar uma teologia moral adequada às estruturas sociais de seu tempo ${ }^{1}$. Isidoro é o grande mestre da teologia polfitica da Alta Idade Média. Tanto quanto Gregório Magno, e mais que Santo Agostinho, provavelmente, ele foi "um homem de ação e mesmo um homem polftico" (Fontaine, 1959, v. 2, p. 705). Dividiu o seu tempo entre os negócios da corte e o estudo dos manuscritos antigos.

Isidoro deixou importante contribuição. Sua obra mantém unidade de inspiração, continuidade de pensamento. Quer se trate de estudo profano, quer de erudição ou de exegese, o objetivo é sempre a elevação de espírito de clérigos e leigos letrados de sua terra (Fontaine, 1959 , v. 2, p. 876-77). Notoriamente apaixonado pela Espanha, esta ocupa importante papel na sua História dos Godos. Tem consciência do passado histórico de sua terra sob o Império. A Espanha não é, assim, para ele uma criação dos godos. Sem o estabelecimento destes na Espanha o regnum Gothorum teria sido apenas um sonho. A realeza gótica encontrou ali ambiente favorável ao seu desenvolvimento. Estabelece sempre uma expressão de continuidade entre os romanos e os godos. Revela incontida admiração pela obra construtiva dos princlpios visigodos. Parece não experimentar nostalgia pela grandeza de Roma e afirma que César foi "o primeiro que deteve o poder monárquico" (Isidoro. Etym. V, 39,25), o que leva J. Fontaine (Fontaine, 1959, v. 2, p. 820), a concluir que "o ancestral dos monarcas visigodos é, para Isidoro, o próprio César". Na verdade, não é homem preso à Antigüidade como Gregório Magno. Isidoro vive seu tempo, liga-se à sua contemporaneidade.

Momento expressivo da evolução do reino ibérico é a formulação, pelo $8^{\circ}$ Concllio de Toledo, do seguinte princípio: "O que faz o rei não é a sua pessoa, é o direito". Esta frase resume o processo que se desenvolve ao longo do século VII e que submete a monarquia visigótica a regras cada vez mais severas. A essa evolução Isidoro esteve de certo modo ligado, mesmo após sua morte. Evidentemente, a realeza da época isidoriana difere da que se desenvolve

1. A otı a fundamental ế a de Fontaine, 1959-83, $3 \mathrm{v}$. 
posteriormente. Não há dúvida, porém, de que a doutrina política de Isidoro resulta de seu contato com a realidade social.

Ao lado de sua Historia dos Godos e das Etymologiae, esta de grande sucesso nos primeiros séculos da Idade Média, Isidoro concorreu para o desenvolvimento da teoria polf́tica. Desde o final da Antigüidade, por sinal, o príncipe cristão aparece como o protetor da Igreja e o defensor da fé. O respeito ao cristianismo era a noção básica. Com Isidoro as teses de Gregório Magno têm uma definição mais clara. Como escreveu Reydellet (Reydellet, 1981, p. 554-55), "a novidade essencial consiste em conceber a realeza não mais como o produto do direito natural, mas como o governo do povo cristão". Acentua-se, desse modo, a noção de serviço. Evidentemente inspirado em Gregório Magno, o autor espanhol identifica-se com o seu tempo, mais precisamente com as transformações por que passava o reino visigodo, que necessitava de uma ideologia nova. Recorde-se, a propósito, que a realeza visigoda se instalou pela conquista pura e simples. Na Espanha, a Igreja não pôde, diante do conquistador ariano, socorrer-se de uma colaboração leal: não há nem um São Remigio espanhol nem um Clóvis visigodo (Reydellet, 1981). Só mais tarde chegam Leandro e Recaredo.

É nas Sentenças que se encontra o essencial das idéias isidorianas acerca da realeza. A obra foi escrita algum tempo depois da morte de Recaredo, rei visigodo que renunciara ao arianismo (589) e se ligara à Igreja. Ao que se crê, redigida no reinado de Sisebuto, cujo excessivo zelo contra os judeus é condenado por Isidoro (Isidoro. Goth. 60,291), que vê neste príncipe uma esperança para a solução dos problemas que afligiam a Espanha após a morte de Recaredo. O princípio de monarquia eletiva de base hereditária, estabelecido pelo IV Concílio de Toledo (633), mostrava falhas. Isidoro compreendeu a necessidade de uma doutrina mais sólida. Prestou inestimável serviço à realeza que dominava a Espanha, livrando-a do seu "pecado original" 2: libertou-a de sua inferioridade diante do Império.

Com efeito, em face da tradição imperial romana, os reinos (bárbaros) que se constitulram no Ocidente pareciam uma fatalidade de histórica absurda. A idéia imperial permanece e exerce constante fascínio sobre as mentes, em sonho que se projeta pelos séculos da Idade Média. Os homens da Igreja procuram "humanizar" os reis bárbaros e criar o ideal de uma realeza cristā. Assim foi com Gregório de Tours, que exerceu grande influência na vida política da Gália merovíngia, e também com Gregório Magno. Essa dificuldade de desembaraçar-se do ideal do Império levou o erudito latino Cassiodoro a mascarar Teodorico de princeps, Isidoro foi mais feliz. Teve a seu favor o advento tardio da monarquia cristã na Espanha. Ao promover a renovação da realeza espanhola, Isidoro exorcizou as lembranças nocivas.

O pensamento político de Isidoro repousa no princípio de que a realeza está a serviço da Igreja. A monarquia não aparece mais como uma imitação fraudulenta do Império, porém como uma instituição a serviço da causa cristã, segundo a vontade de Deus. A Igreja assume o princlpio da universalidade do Império, em virtude da nova concepção do mundo. No entanto, ao contrário da idéia original de Império, que é, por definição, unitária e totalitária, a lgreja admite pluralidade: sustenta a unidade da realeza de Cristo, mas, sendo universal, compōe-se de múltiplas células. Esse pensamento já havia sido, aliás, exposto por Gregório Magno na polêmica com o patriarca oriental João, o Jejuador.

Ao conceber a realeza como um serviço do povo cristão, Isidoro, indiscutivelmente, assimilava-a ao episcopado. "Inventando a realeza cristã - escreveu M. Reydellet (Reydellet, 1981 , p. 557) - ele libertava do Império as realezas nacionais e lhes conferia uma legitimidade própria ${ }^{3}$. Tal sistema político parte da afirmação de que a Igreja constitui o regnum Christi. A teologia polticica de Isidoro é cristológica por excelência. Ao tornar-se cristāo o príncipe, alterase a natureza do seu poder. Modifica-se, igualmente, a maneira de exercé-lo. Estabelece-se, dessa forma, estreita relação entre a realeza e a Igreja, vale dizer, entre o Estado e a Igreja; do

2. A expressăo \& de M. Reydellet, 1981, p. 556.

3. O sistema polftico-religloso isidoriano parte da afirmaçăo de que a lgreja constitui o regnum Christi $\theta$, portanto, da realeza de Crlsto. Diferente da concepçáo de monarquia divina, que servia de fundamento ao antigo poder imperial romano. 
mesmo modo, cria-se novos laços entre governantes e governados. Esse traço de igualdade entre todos, de comunhão sob a autoridade de Cristo, dá especial originalidade à teoria isidoriana de poder.

A realeza de Cristo ocupa, pois, lugar preeminente no pensamento de Isidoro. $O$ sevilhano nāo é movido por razōes políticas, mas pela necessidade da luta doutrinária que iria liderar na reconstrução da realeza visigótica. Essa realeza não aparece aos seus olhos como uma espécie de Império universal modelado segundo a imagem do Império terrestre, porém se perpetua através dos séculos. A realeza de Cristo, de que a realeza judaica é imagem, não exprime poder e dominação: não é a do Cristo pantocrático dos mosaícos bizantinos. Essa realeza de Cristo se exerce no interior da Igreja de que Cristo é o Esposo. Segundo Marc Reydellet, Isidoro assimilou de maneira admirável o sentido dessa imagem de Rei e Esposo consagrados pela mesma unção. A crítica moderna explica a unção real como um rito de participação, de interação. Isidoro soube traçar a especificidade dessa realeza tal como ela se define, ideal e figuramente, na unção dos reis judeus. A unção em si é tão somente um símbolo. Diferentemente do Antigo Testamento - em que a unção real expressa a vontade divina e pode permanecer secreta -, a realeza cristã é concebida na Igreja e fundada na noção de devotamento e subordinação reclprocos ${ }^{4}$. Não existe qualquer comprovação da existência do rito de unção real na Espanha visigótica da época de Isidoro. Não há dúvida, porém, de ter sido o reino ibérico o primeiro a realizar tal cerimônia. Convertidos ao catolicismo, seus reis foram os primeiros a receber a sagração, isto é, a unção sacramental que lhes conferia excepcional prestígio ${ }^{5}$.

$O$ rito é, com efeito, secundário e reflete o simbolismo, lembra Pierre Batiffol. Dele se vale Isidoro para concretizar o conjunto de representações, ao retomar os ensinamentos de Gregório Magno e Santo Agostinho. A única unção que conta verdadeiramente é a unção batismal, que torna o povo cristão um conjunto harmonioso sob a autoridade de Cristo. Dessa idéia fundamental do cristianismo, Isidoro formulou verdadeiro sistema político. Sabemos que a noção de que o rei faz parte da Igreja vem da Antigüidade, mais precisamente de Santo Ambrósio. Com Isidoro a realeza aparece como expressão política do corpo místico.

Sempre próximo do pensamento de Gregório Magno, Isidoro preocupa-se com os perigos do poder. Por isso, dirige-se aos reis, futuros soberanos e pretendentes à realeza. Tece consideraçōes acerca de acontecimentos contemporâneos. O poder para ele não é sinônimo de perdição. Apenas exige do seu detentor uma força espiritual superior. As reflexões que aparecem nas Sentenças a propósito da realeza demonstram sua preocupaçāo de pastor. Assim é que, ao retomar a teoria cristã sobre a origem do poder, ligando-a ao plano da salvação, põe em relevo a modificação introduzida pelo cristianismo no plano social. Não se trata apenas de colocar o príncipe a serviço da Igreja. É a própria essência da realeza que se transforma - a instituição real é na verdade uma função no interior da sociedade. Embora o fundamento das idéias de Isidoro estejam sobretudo em Santo Agostinho e Gregório Magno, foi ele o primeiro a dar formulaçăo mais nítida a esses principios ${ }^{6}$.

Nas Etymologiae, sua obra "mais completa pela concepção e realização" (J. Fontaine), o

4. J. de Pange salienta que é necessário distinguir na unçăo hebraica o ato declarativo e o ato constitutivo. $O$ primeiro realiza-se sempre secretamente. O segundo é um rito coletlvo, cujo agente "est toujours pluriel". Pange, 1949, p. 49. Na realeza cristă a unçấo $\delta$ um rito unicamente declarativo. Existe, portanto, significativa alteraçáo em relaçáo aos costumes judai$\cos$, pois $\theta$ através do ato declarativo que se manifesta a coesăo do povo, que, na Bßblia, se expressa pelo ato constitutivo. Decorre dal que a unçăo do príncipe cristăo nâo poderia ser conslderada como mera reconstituiçăo do rito judaico. Cf. Reydellet, 1981, p. 562, nota 220.

5. Marc Bloch cré que a introduçăo do rito de sagraçăo na Espanha visigótica seja anterior a Wamba. Baseia-se em Jullano de Toledo, que atesta sua existéncia desde 672. Bloch, 1983, p. 461. Marcel David refutou o argumento. Aflrma que Juliano de Toledo apresenta como uma institutçăo em vigor apenas o juramento prestado pelo rel. O fato de o rel Wamba ter sido sagrado na Igreja pretoriana de Toledo, năo prova a existencia de uma tradiçăo anterior. David, 1950, p. 39-46. A igreja pretoriana, ou de Sâo Pedro e Sáo Paulo, era onde se oflciavam as grandes cerimônias nacionais - bênçăo do exerctto e preces do rel antes de partir para a guerra. Nela reuniurse o vill Concilio de Toledo e outros seis grandes concfllos ali tiveram lugar at仓 702. J. de Pange, 1949, p. 122. Năo se deve prentender, entretanto, que o testemunho de Jullano de Toledo exclua a hipótese de uma sagraçă̌o anterior a 672. Contudo, năo existe qualquer prova formal.

6. J. Fontaine afirma que Isidoro "tentou construir uma teologla moral adaptada às estruturas sociais do reino visigotico". Fontaine, 1959, v. 1, p. 10. 
prelado revela seu ideal do rex ao indicar a origem do nome: "o nome de rei vem de agir com retidāo" (Isidoro. Etym. IX, 3,18). Ao tecer considerações sobre as virtudes do rei, assevera:

"As virtudes reais essenciais são em número de duas: a justiça e a piedade. Mas, entre os reis, a piedade é a mais louvável; porque a justiça, por si própria, é mais severa" - "Regiae virtutes praecipuae duae: iustitia et pietas. Plus autem in regibus laudatur pietas; nam iustitia per se severa est" (Isidoro. Etym. IX, 3,5).

Nas Sentenças, obra pastoral, cuida de como deve agir o soberano. Em Gregório, a palavra rex tem interpretação laudatória. Isidoro não foge muito a isso e segue de perto a tradição legada pelo estoicismo segundo a qual sábio é o rei ?

Para Isidoro a realeza deve ser, antes de tudo, uma realeza em si mesma; o verdadeiro rei sabe dominar seus instintos e resistir a si próprio. Saliente-se que, em Isidoro, rex é a única palavra carregada de um peso metafórico. Princeps, que aparece várias vezes nos caṕltulos das Sentenças, parece ter um valor puramente institucional; o sevilhano não acompanha a Gregório Magno, que via, por detrás do princeps, um repositório de espiritualidade. De resto, ao formular o seu ideal de rex, Isidoro não the empresta o alcance de um princípio constitucional. Não prega que o rei que peca deva ser destronado. Seu ponto de vista é o da gramática e da metaff́sica: o rei que falta a seus deveres trai seu nome e seu missão (M. Reydellet).

O perfil do príncipe cristāo isidoriano acompanha o modelo esboçado por Gregório. Parece que Isidoro considera a exegese de Gregório mais adequada à moral política que ele tenta impor no reino ibérico. É impelido a Gregório possivelmente por razão particular. A óptica de Santo Agostinho, de duas cidades em confronto, reflete a observação de um mundo pagão; a perspectiva de Gregório e de Isidoro é a de uma sociedade cristã. A transferência que se processa aplica-se ao novo povo de Deus, isto é, o povo cristão. Em suma, no que diz respeito aos perigos do poder, ao ideal do rex ou à doutrina do mau rei, o pensamento isidoriano fundamenta-se intimamente en Gregório Magno. Assim é que pede ao rei que refreie sua cupidez e adverte que o bom príncipe "não despoja ninguém para fazer um pobre rico" (Isidoro, Sent. III, $49,2)$. Quem encarnaria a imagem do príncipe cristāo de Isidoro? O retrato que nos oferece parece ser o de Recaredo.

O grande problema que se coloca a Isidoro é o de saber o caminho a tomar depois da conversão de Recaredo. Em outros termos: qual o significado da realeza em uma sociedade cristã? Não se tratava apenas, como observa M. Reydellet, de definir as relações entre a lgreja e o Estado. $O$ grande perigo era ver o soberano visigodo tentar submeter a Igreja, a exemplo dos imperadores. No momento em que a realeza espanhola procurava seu caminho era importante revesti-la de uma justificação ideológica, ou seja, daquilo que um historiador das idéias políticas chamou de helenismo cristão ${ }^{8}$. Essa teoria, originada de Eusébio de Cesaréia, autor de importante História Eclesiástica, era a doutrina oficial do Império Bizantino, a partir de Justiniano e seus sucessores.

Esse foi o quadro de que se valeu Isidoro para elaborar sua concepção política. É dentro dessa perspectiva que esboça seu modelo do principe cristāo. Antes de definir as qualidades do principe, ele pergunta a que critério deve o rei responder em uma sociedade cristā. Diante da gravidade do momento, assume a orientação da realeza. Com efeito, toda a doutrina política de Isidoro fundamenta-se na interação Igreja-Estado. $O$ texto que trata das relaçōes entre os dois poderes tem sido objeto de interpretações exageradas. Não será, pois, demais repeti-lo:

"Os príncipes seculares ocupam, por vezes, a supremacia do poder na lgreja a fim de proteger, através desse poder, a disciplina eclesiástica. De resto, na lgreja esses pode-

7. Para um estudo aprofundado do sentido da etimologia em Isidoro, cf. Fontaine, 1959, v. 1, p. 43.

8. Dvornik, 1966, v. 2, p. 611 ss. 
vale-se da realeza terrena: quando aqueles que estão na lgreja vão contra a fé e a disciplina, são destruidos pelos príncipes. Que estes saibam que Deus thes pedirá contas a respeito da lgreja, por Ele confiada à sua proteção. Pois, quer a paz e a disciplina eclesiástica se consolidem pela ação de príncipes fiéis, quer periguem, Aquele thes pedirá contas, já que confiou sua lgreja ao seu poder" (Isidoro. Setentiae. III, 51. PL 83, 723-24. Apud ARQUILLIERE, 1956, p. 142).

Examinado isoladamente, este texto parece indicar o esvaziamento o conteúdo próprio do Estado, isto é, presta-se a uma interpretação teocrática. $O$ trecho que precede essa citação é particularmente importante. Nele afirma Isidoro:

"Os poderes seculares estão sujeitos à disciplina religiosa; e não obstante disponham da supremacia real, continuam ligados pelos laços da fé". (Isidoro. Sent. III, 51, 3, PL 83, 723).

Se ligarmos as duas passagens, vemos que, em relação à lgreja, o príncipe the deve sujeição; em alguns casos, não obstante, conserva seu poder dentro da lgreja - isso quando chamado a assegurar a disciplina diante da impotência da autoridade eclesiástica. $O$ texto abrange os limites da intervenção do poder civil no interior da lgreja. Não se trata, portanto, de submeter o Estado ao poder religioso. As intervençōes do poder leigo nos negócios da lgreja resultam dos deveres desse mesmo poder, que os príncipes receberam de Deus "para afastar os povos do mal". Não objetivam transformar esse poder de natureza secular em poder eclesiástico ou supra-eclesiástico. Mas é inegável: estamos bem distantes do dualismo gelasiano.

Marcel Pacaut viu com lucidez o postulado isidoriano ao escrever: "Portanto, não se diz mais que a Igreja dá ao Estado seu dinamismo nem mesmo que o Estado está na Igreja (o que implicaria subordinação), mas simplesmente que, sem o serviço da lgreja e sem a fé cristã, não há nenhuma razão para haver o Estado, nāo há o Estado justo" 9 . O estudo literário de Marc Reydellet do texto de Isidoro sustenta que o prelado espanhol, "bien loin de vouloir vider l'État de son contenu propre, met ici en garde contre les empiètements du prince sur le domaine ecclésiastique. II lui reconnaît seulement le droit d'intervenir pour suppléer à l'impuissance des clercs" ${ }^{10}$. Tenha-se em mente que Isidoro vive numa Espanha tardiamente convertida. À vista disso, acautela-se contra os males de uma interferência indevida do Estado em matéria doutrinária. É infenso ao príncipe travestido de teólogo. De qualquer forma, porém, essa filosofia política irá sustentar, um século mais tarde, o edificio carolíngio.

Nota-se em Isidoro, como se afirmou, uma definição mais precisa dos postulados expressos por Gregório Magno no que concerne ao papel do poder leigo na manutençāo da disciplina e da moral cristās. A monarquia isidoriana torna-se um ministério, uma função na sociedade. Estamos diante de uma sacralização do poder temporal. Pode-se dizer que, como Gregório, o pensamento de Isidoro é dominado por um desejo de "unificação", que não deve confundir-se com um projeto teocrático ${ }^{11}$. Pode-se até admitir uma negação do direito natural, mas não uma absorção do Estado pela Igreja. Certamente, ao atribuir ao poder temporal função religiosa, a doutrina eclesiástica gerou certa confusão entre os poderes. Todavia, não era ainda chegado o momento de substituir a teocracia imperial pela teocracia pontifícia.

Na realeza de Isidoro há duas fontes de poder: Deus e o povo cristão. É Deus quem dá o

9. Pacaut, 1989 , p. 30. A primeira ediçāo desta obra é de 1957. Dvornik tem opiniăo bem próxima: "In these words the notion of the state built on natural law had almost disappeared. The state is necessary only for the protection and defense of the Church. If the Church did not need such protection and defense, the secular power would not be necessary, since this is its sole reason for existence". Dvornik, 1966, v. 2, p. 848.

10. Reydellet, 1981, p. 590.

11. Ao sustentar a concepção ministerial de poder, Arquillière atribui a Isidoro poderosa influência teocrática e estabelece estreita relaçăo entre o pensamento do sevilhano e o de Gregório VII (Arquillière, 1956: 42 e 142). De sua parte, Ullmann acredita ter sido Isidoro um dos principais arquitetos da idelologia hierocrática e o mais perfeito continuador das idéias de Gelásio (Ullmann, 1955: 28-31). Cf. ainda as opiniós de Carlyle, 1903, v. 1, p. 171 ss e de Arcari, 1968, p. 717 ss. 
poder, mas o rei é também convocado pela comunidade de fiéis. O rei representa, no domínio leigo, o sinal da unidade orgânica do povo, da mesma maneira que o bispo o é no plano espiritual. Temos, assim, uma realeza fundada, não nas pessoas, porém na comunhão de fiéis. Esta concepção distingue-se nitidamente da ideologia imperial, que repousa na idéia de que a realeza é imitaçāo de Deus. À noção de poder originado do alto por delegação, Isidoro cria uma realeza cuja origem é Deus, mas que tem sua causa final no corpo místico dos fiếis unidos no Cristo. Em vez de ser apenas um delegação divina, a realeza é, ao mesmo tempo, uma participação com a humanidade. Em resumo, o poder de Deus encarnado em certos homens iguais a outros homens, ligados pela uniāo em Cristo ${ }^{12}$.

O rei está obrigado a respeitar as leis, afirma Isidoro (Isidoro. Sent. III, 51,1-2). A questão já havia ocupado os melhores círculos romanos: o princeps sobrepōe-se ou não às leis? A teoria segundo a qual o soberano é a "lei viva" aparece no primeiro século do Império, por influência helenistica ${ }^{13}$. A noção de que o imperador está sujeito às leis é traço marcante do principado, que desde suas origens procurou exorcizar a má ascendência das idéias orientais. Santo Ambrósio adotou posição ambigua: ao mesmo tempo em que fazia concessão ao principio helenístico da "lei viva", exigia do imperador obediência às leis. Embora pareça hesitante em alguns traços, Isidoro submete o príncipe ao ordenamento legal. Nesse sentido, liga-se ao ideal de civilitas do Alto Império.

É importante salientar, pois, a transformação que se opera na noção de poder pessoal, substitulda pela idéia de poder como missão. É a lgreja o agente dessa transformação, que faz do poder não um privilégio, mas um serviço a ser exercido em beneficio da coletividade. Em ministerium Dei torna o Estado um instrumento de salvação. Consubstancia-se na elaboração teórica do Império Cristão. Louve-se, entretanto, o meritório esforço de Isidoro de criar uma nova imagem de soberano necessária ao nascimento da Europa.

\section{Résumé:}

Après la chute de l'Empire romain, l'Église voulait définir l'attribuition des pouvoirs au terme d'une étroite unité, c'est-à-dire, sans distinguer le pouvoir temporal du pouvoir spirituel. Isidore de Séville est le grand maître de la théologie politique de Haut-Moyen Age. Il délivre la royauté espagnole de son "peché originel": la libère de son infériorité devant l'Empire et exorcise les souvenirs nocifs. En "inventant" la royauté chrétienne, il confère une légitimité propre aux royautés nationales de l'Occident. Mas la notion de service que le christianisme attribue au pouvoir fait de l'Etat un instrument de salut. 


\section{CLASSICA}

Classica é publicada anualmente pela Sociedade Brasileira de Estudos Clássicos, incluindo trabalhos inéditos sobre todos os aspectos da cultura da Antigüidade clássica e de outras culturas com elas relacionadas. $O$ primeiro volume foi lançado em 1988, aparecendo no ano seguinte o volume 2. O volunie 3 (1990) encontra-se no prelo, compreendendo os seguintes trabalhos:

Filosofia e religião na Grécia antiga - Sally C. Humphreys

Discurso utópico e ação política na República de Platão - M. G. M. Augusto

O gênero deliberativo na oratória grega - I. B. B. Fonseca

A verdade lucreciana - M. G. Novak

La medicina en la India antigua - J. M. Mora

La religion de l' Antique: de Ciceron a Chateaubriand - S. Gély

The Shield of Achiles and the Temple of Venus - S. L. Schwartz e J.P. Mendes

Perspectivas de alterida em Luciano de Samósata - J. L. Brandāo

La literatura judia helinística - A. Piñero

Elementos para uma leitura semiótica das representaçōes na cerâmica grega antiga - J. A. D. Trabulsi

Integram ainda o volume resenhas críticas, noticias bibliográficas e, na seção intitulada "Instrumentos de Pesquisa", ensaio de C. Jacob sobre "L'Année Philologique".

Os interessados poderão solicitar a assinatura de Classica através do preenchimento do cupom reproduzido no verso desta folha.

O preço da assinatura é de US\$ 10 (Brasil) e US\$15 (exterior).

Os sócios da SBEC recebem gratuitamente tanto os números regulares de Classica quanto os suplementos. 


\section{SOCIEDADE BRASILEIRA DE ESTUDOS CLÁSSICOS COMISSÃO DE INTERCÂMBIO CIENTÍFICO}

\section{Caixa Postal 905}

30161 - Belo Horizonte

BRASIL

cupom de assinatura de Clássica

Nome do Assinante:

Endereço:

CEP:

Cidade:

\section{Observaçōes:}

1. O cupom bancário para o pagamento da assinatura será enviado pela Comissāo de Intercâmbio Científico ao interessado, tão logo seja recebido o pedido de assinatura.

2. A assinatura só será confirmada após a quitação do valor correspondente através do sistema bancário.

3. O cupom assim deve ser remetido para o endereço indicado no alto da foIha. 